\title{
Lunar e-Library: A Research Tool Focused on the Lunar Environment
}

\author{
Tracy A. McMahan ${ }^{1}$ and Charlotte A. Shea ${ }^{2}$ \\ Qualis Corporation, Huntsville, AL, 35806, USA \\ Miria Finckenor ${ }^{3}$ and Dale Ferguson ${ }^{4}$ \\ Marshall Space Flight Center, Huntsville, AL, 35812, USA
}

\begin{abstract}
As NASA plans and implements the Vision for Space Exploration, managers, engineers, and scientists need lunar environment information that is readily available and easily accessed. For this effort, lunar environment data was compiled from a variety of missions from Apollo to more recent remote sensing missions, such as Clementine. This valuable information comes not only in the form of measurements and images but also from the observations of astronauts who have visited the Moon and people who have designed spacecraft for lunar missions. To provide a research tool that makes the voluminous lunar data more accessible, the Space Environments and Effects (SEE) Program, managed at NASA's Marshall Space Flight Center (MSFC) in Huntsville, AL, organized the data into a DVD knowledgebase: the Lunar e-Library. This searchable collection of $\mathbf{1 1 0 0}$ electronic (.PDF) documents and abstracts makes it easy to find critical technical data and lessons learned from past lunar missions and exploration studies. The SEE Program began distributing the Lunar e-Library DVD in 2006. This paper describes the Lunar e-Library development process (including a description of the databases and resources used to acquire the documents) and the contents of the DVD product, demonstrates its usefulness with focused searches, and provides information on how to obtain this free resource.
\end{abstract}

\section{I. $\square$ Introduction}

W hen the President announced the Vision for Space Exploration in January 2004 and directed NASA to

return to the Moon and use this experience as a stepping stone for exploring Mars and other worlds, there were no completed architecture plans or requirements documents. The Ares and Orion exploration spacecraft were not even twinkles in an engineer's eyes. Engineering efforts across NASA were rightly focused on returning the Space Shuttle safely to flight and operating the International Space Station (ISS). Yet this bold new vision energized engineers and scientists and made them look toward the Moon - a location last visited by humans in 1972.

In recent years, many of the engineers and scientists at NASA and aerospace companies have focused their efforts on learning to live and work in low-Earth orbit, the environment in which the Space Shuttle and the ISS operate. They have learned valuable lessons not only about building and operating large structures in space but also about collaborating with international partners on space research projects. They have a thorough understanding of the low-Earth-orbit environment and the hazards it poses: atomic oxygen, plasma interactions, ultraviolet radiation, and $\mathrm{meteoroid} / \mathrm{space}$ debris impacts to name a few.

While many of these same hazards pose threats to lunar missions, the lunar environment is different from the low-Earth orbit environment. Another consideration is that low-Earth orbit is closer to home than the Moon, so it is

${ }^{1}$ Technology Historian, Qualis Corporation, 5000 Bradford Drive, Suite 3B, Huntsville, AL 35805, AIAA Member.

${ }^{2}$ Publications Specialist, Qualis Corporation, 5000 Bradford Drive, Suite 3B, Huntsville, AL 35805.

${ }^{3}$ Materials Engineer, Materials and Processes Laboratory, Environmental Effects Branch, Mail Stop EM50, NASA Marshall Space Flight Center, AL 35812, AIAA Associate Fellow.

${ }^{4}$ Materials Engineer, Materials and Processes Laboratory, Environmental Effects Branch, Mail Stop EM50, NASA Marshall Space Flight Center, AL 35812, AIAA Senior Member. 
easier for crews to return home or be rescued from environmental hazards. Most engineers today have little or no hands-on experience in designing human-piloted vehicles to go to the Moon, support long lunar missions, and return safely to Earth. The Lunar e-Library research effort started with the idea that a good step in preparing for any type of lunar mission would be to acquire as much knowledge as possible about the lunar environment - including lessons learned about getting to the Moon, living there and returning to Earth - and to organize that information so that it would be readily available and accessible to NASA and aerospace professionals who would be planning and implementing the Vision for Space Exploration.

\section{Guiding Philosophies}

In 2004, the NASA engineers who started this data collection project were working long hours analyzing External Tank insulating foam and preparing the Space Shuttle for return to flight. Most of their efforts were concentrated on materials and processes and on the launch environment. Their current work was visible evidence of the necessity to understand precisely the environment and its effects on materials. To go back to the Moon successfully, they knew they would need to know about myriad environments: (1) launch (2) low-Earth orbit, (3) the cis-lunar environment, and (4) the lunar environment. These engineers also realized the challenges of long-duration flights and recognized that materials, which worked well for a 12-day Apollo missions might not work for an extended mission. In addition, many materials might not still be commercially available after 30 years, and some Apollo-era materials have been banned from use because of environmental or health concerns.

Rather than pursue this quest individually, leaders from NASA's Space Environments and Effects (SEE) Program at the Marshall Space Flight Center (MSFC) in Huntsville, AL, and from the Materials and Processes Laboratory in the MSFC Engineering Directorate combined their resources to mine the numerous collections of existing data and create an extensive but more manageable compilation of lunar data. Their goal was to identify knowledge from the past that would enable the future return to the Moon.

They also had the foresight to realize that while some sources of valuable information would be easy to find and identify, for example, the Apollo Mission Reports, some more obscure yet invaluable publications or data might be lost or hard to locate. Who were the best people to lead them to these resources? They were the people who helped NASA successfully journey to the Moon during the Apollo/Saturn Program. Where were these people? Many of them had retired, and many were about to retire. NASA scientists and engineers suggested interviewing the experts: the Apollo scientists and engineers who successfully enabled the first human missions to another world. These experts could not only identify valuable sources of documents and data but also could relate personal experiences information that might not appear in any formal documentation.

\section{A. Locating Resources and Data Archives}

One goal of this project was to provide a research tool that did not duplicate current resources but made use of existing resources to capture data on the lunar environment. The NASA Aeronautics and Space Database, which is available to NASA civil servants and contractors with NASA computer IP addresses, has 3.9 million citations that date back to the early $20^{\text {th }}$ century and the days of the National Advisory Committee for Aeronautics (NACA). It is a wonderful resource that can be searched in many ways (author, title, NASA report number). When the project began, this new arm of NASA's Scientific and Technical Information (STI) network was about a year old. All new documents were in digital format, but requests had to be submitted for scanning many of the older Apollo-age documents, such as the Apollo Experience Reports collection and even many of the Saturn Flight Evaluation Reports and Apollo Mission Reports.

Other resources, such as the Apollo Lunar Surface Journals web site and the Johnson Space Center Oral History web site, provided valuable documents: transcripts of the air-to-ground transmissions during the Apollo missions and interviews with Apollo astronauts. In addition to NASA's extensive online collections, history offices, and document repositories at NASA Headquarters and the field centers, private collections were available through other online sources. Retirees had donated documents to archives at the University of Alabama in Huntsville, the University of Houston in Clear Lake, Texas, and the U.S. Space and Rocket Center in Huntsville, to name a few locations. Lunar e-Library researchers also consulted with MSFC Historian Michael Wright, as well as other archivists and historians, who offered insights into their collections.

The Smithsonian National Air and Space Museum Collection had not only documents but also extensive collections of artifacts, such as the world's largest collection of space suits. NASA materials engineer Miria Finckenor, co-author of this paper, was able to inspect this collection and interview curator Amanda Young about 
the material degradation that had occurred in the suits. A paper in the Lunar e-Library collection describes the Smithsonian's analysis and work to preserve the space suit collection.

To bolster research and make other resources readily available without duplicating them, the Lunar e-Library DVD includes a descriptive list and web links to sites containing document sources, databases, and oral history interviews identified during the effort.

\section{B. Focusing the Collection on the Lunar Environment}

The goal of the Lunar e-Library effort was to create a product that would be valuable to working engineers and scientists. Therefore, it was imperative that these people guide the product from start to finish. The technical experts focusing the research decided that the collection should focus on documents that could provide information on (1) the space and lunar environment, including launch and landing environments for vehicles such as the Saturn V and other Apollo Program spacecraft and (2) materials research. To properly mine existing collections for the best documents, engineers and scientists helped develop a set of key words that focused on areas of interest within these broad topics.

Key words described almost every aspect of the lunar environment: atmosphere, gravity, dust, lighting, and temperature. Another layer of key words dug deeper down into particular subjects of interest. For example, for dust, the second layer of key words included such topics as lunar mobility, electrostatic charging, soil composition, dust mitigation, contamination, magnetism, and even lunar soil constituents, such as ilmenite or nanophase iron. The goal was to collect information about the launch, space and lunar environment that would be useful as NASA developed new launch and crew vehicles, extended operations experience in a hostile lunar environment, and developed capabilities and technologies (particularly in the area of materials and processes) that would enable the Moon to be used as a stepping stone for exploring Mars and the universe beyond.

In addition to identifying topics of interest, technical experts helped develop a list of pertinent categories of documents that were likely to contain lunar environment information:

A. Apollo Mission and Preliminary Science Reports

B. Saturn V Flight Evaluation Reports

C. Key historical documents and summary documents that contained data and/or the recollections of the Apollo crews, engineers, and scientists

D. Saturn V hardware documents, particularly those dealing with materials and processes or the launch environment

E. Apollo Experience Reports

F. Space Vehicle Design Criteria documents developed after Apollo and before the Space Shuttle, particularly those dealing with the space environment or materials

G. Data from lunar missions: Surveyor, Apollo, Clementine, Lunar Prospector, etc.

H. Lunar Roving Vehicle documents

I. Major lunar reference missions and studies, especially for the Space Exploration Initiative and the First Lunar Outpost.

A vast amount of data existed in many locations and in both digital and hard formats, but with the help of historians and the experts that we interviewed, key documents were identified. The final collection is not allinclusive but has enough crucial documents that include bibliographies and other references to give researchers a good start in finding critical information related to the Moon.

\section{III. $\square$ Putting Space History to Work}

Once data collection was under way, it became clear that NASA engineers needed to use lunar environment data in their current work. Research teams needed this information to help guide architecture studies and planning. They were asking questions and looking for answers: What is the lunar dust really like? How big a problem was dust for Apollo astronauts? What studies were accomplished before the Apollo missions? How well did the Lunar Roving Vehicle thermal protection system work? What kind of rovers would best benefit future lunar missions? What is the environment at the Moon's South Pole? What scientific tasks would we need to accomplish to set up a base there and in other lunar locations? NASA and contractor researchers were already at work examining these and many other issues. Many answers could be found in previous reports and studies in which Apollo astronauts had talked 
about their experiences on the Moon and in which scientists had published data from lunar experiments or remote sensing probes.

As information was compiled, Subject Matter Experts (SMEs) were invited to assess the literature's value. A tracking database was designed to log in all collected documents, along with bibliographic information: title, author, key words, source, data release restrictions, etc. The tracking database included a searchable index to avoid document duplication and make it possible to search the entire collection for specific documents. The documents were posted on an internal MSFC server where registered users could download them for use in technical projects. At the same time, the SMEs provided input on which documents were valuable and recommended other documents for inclusion. They requested in-depth literature searches on special topics of interest: lunar dust, the lunar poles, contamination, radiation, lunar science, the lunar atmosphere and plasma environment, Saturn $\mathrm{V}$ tanking issues, Saturn V heat shield design, the Apollo Command Module cooling and thermal control systems, and space suit design - and the results of these searches were added to the e-Library. Engineers and scientists were putting space history to work immediately in their everyday jobs.

\section{A. Interviews}

In addition to the literature collection, researchers determined early in the project that it would be wise to consult experts who worked on the Apollo program. These experts provided guidance on valuable documents and studies and were interviewed to obtain information that did not exist as part of formal documentation or supplemented information in formal documentation. Focused interviews ( 1 to 4 hours long) were conducted with 16 people; many were retired, but most still support aerospace programs as contractors, consultants, or researchers.

Interview subjects were selected to address a variety of topics, and some critical topics were recommended by the SMEs. While some of the interview subjects became managers, all started their careers in the trenches during the Apollo/Saturn era. Since numerous interviews had already been conducted with top NASA officials and the Apollo astronauts, this effort aimed at interviewing key managers, engineers, and aerospace employees who worked on the Apollo/Saturn program. Many of them started their NASA careers at that time and transferred that knowledge to the Space Shuttle Program and other efforts, such as the Hubble Space Telescope. Their early experience influenced later projects and applied not only to engineering topics, such as rocket engine design, but also to other areas such as system engineering, and non-technical topics such as mentoring, education, and communications.

The interview topics included Saturn rocket design, the history of engine design from the early missiles to the Space Shuttle Main Engines, the Lunar Roving Vehicle design, dust problems, thermal control, lunar surface studies, and project management; materials selection and materials processes such as welding, materials requirements and testing for metals and non-metals; and many aspects of the space environment with particular emphasis on materials durability and dust.

Since the number of interviews was limited as was the time for each interview, each was focused on select key topics. This strategy also allowed correlation and comparison of the answers to certain interview topics. Researchers worked with the SMEs to develop a questionnaire in which the majority of questions focused on the lunar environment and materials and processes, with a few general questions aimed at lessons learned. Interview subjects were requested to return this completed questionnaire along with a biography, a list of publications, and a list of publications that they recommended for inclusion in the Lunar e-Library. This information, along with additional input and specific questions submitted by SMEs was used to create a more in-depth set of interview questions for the oral interview.

SMEs also participated in the interviews. In one interview, for example, a materials specialist asked a series of questions related to how welding criteria were developed and established for large space structures. During an interview with a lunar scientist, engineers developing methods for in situ resource utilization asked a series of questions related to lunar soil properties and the potential of specific processing techniques. A contamination expert asked an Apollo engineer who had worked on the lunar roving vehicle design about dust studies and control methods.

The interviews were recorded by digital video or audio. The final Lunar e-Library DVD contains a short biography of each interview subject and the interview questions. The DVD also links to many web-based interview collections, such as those conducted by the Johnson Space Center Oral History Program, the NASA Alumni League, and the Smithsonian Air and Space Museum Oral Histories, as well as lists of collections available at NASA Centers. 


\section{B. The Lunar e-Library DVD Product}

The final Lunar e-Library DVD product is an export-controlled, searchable knowledge database (Fig. 1). The technical experts guiding this project wanted to ensure that the information was not only collected but that it was made readily accessible. The DVD product features an easy-to-use Acrobat-based search engine that employs key words to search through the entire 1100 documents at once, lists the documents by relevance, and takes the user directly to the key words in the various documents (Fig. 2). A document index also is included so that the user can check for particular documents of the interest and then conduct advanced searches by title, author, and other information criteria.

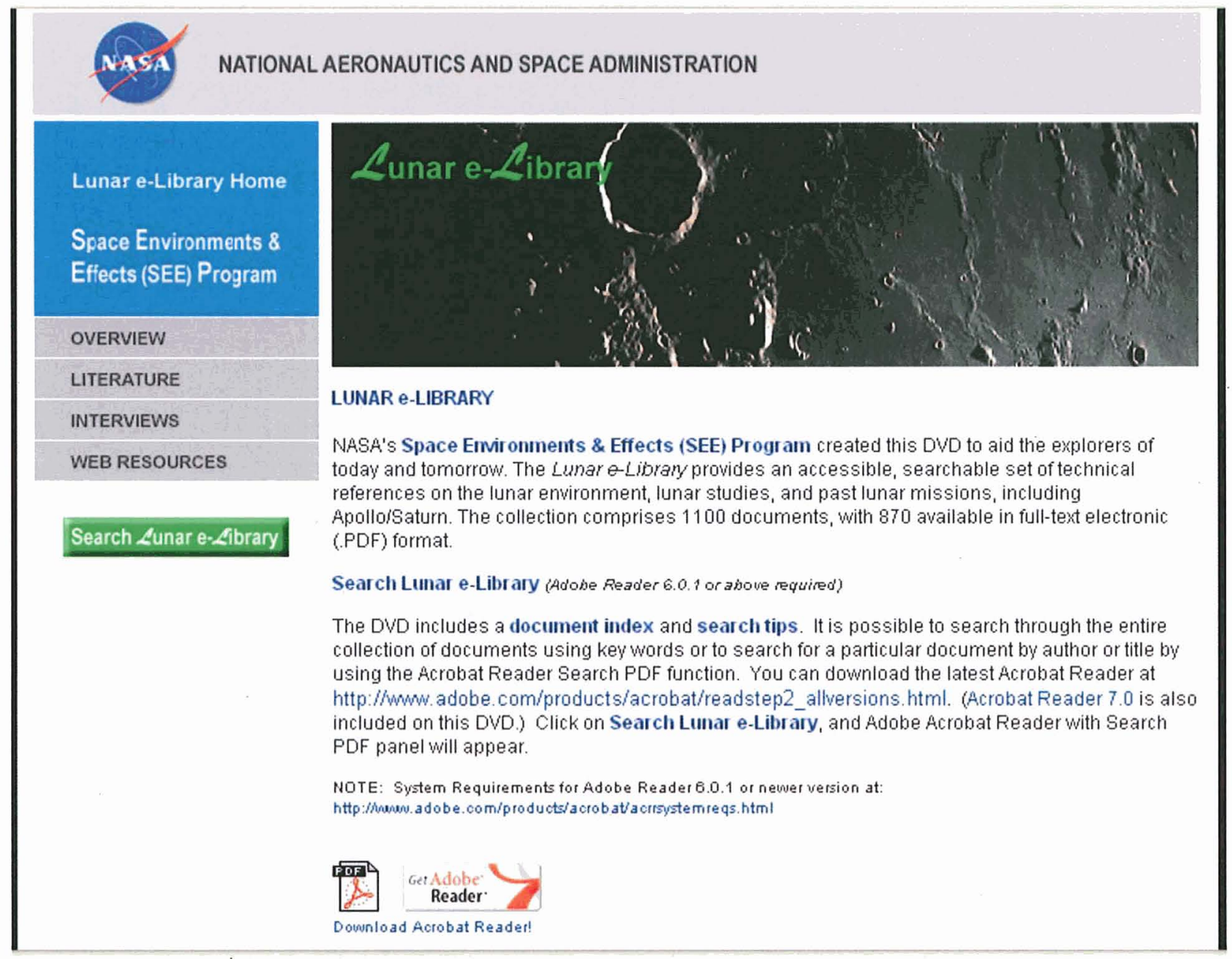

Figure 1. Lunar e-Library home page. 


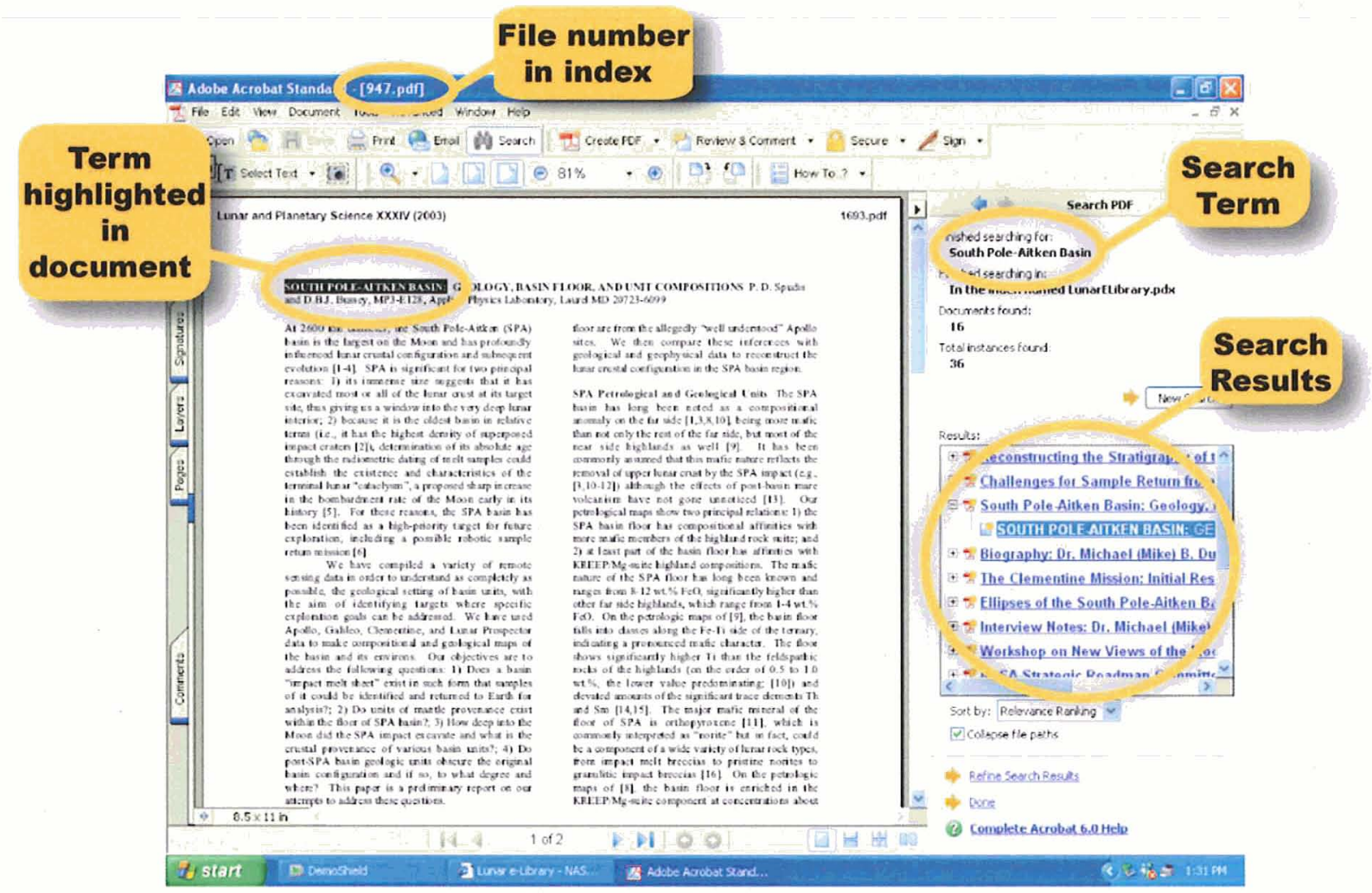

Figure 2. Sample search results.

In addition to documents, the DVD includes a section on the interviews conducted for the project, a description of the literature collection process, and a web resources section that links to numerous online collections of documents as well as databases and image libraries.

Although the DVD is export controlled, it is free and can be ordered by NASA and aerospace professionals by filling out two forms, located on the SEE web site (Fig. 3):

(1) The SEE Product Access Form: an online form required for export-control purposes. Click on SEE Product Access Form to fill it out and submit it online.

(2) A SEE Product Access and Software Release Agreement Form: required for software licensing agreements. It must be printed, filled out, and faxed to Sopo Yung, the SEE software developer, at 256-544-8480. To print the form, under General on the Web page, click on Lunar E-Library-knowledgebase.

Both forms are located at:

http://see.msfc.nasa.gov/ModelDB/ModelDB.htm

This DVD is designed to operate with Windows-based operating systems. More details and computer system requirements for running the Lunar e-Library DVD, and information for downloading Acrobat Reader 7.0 are posted on the SEE Web site at:

http://see.msfc.nasa.gov/dmia/LunarELibrary.htm 


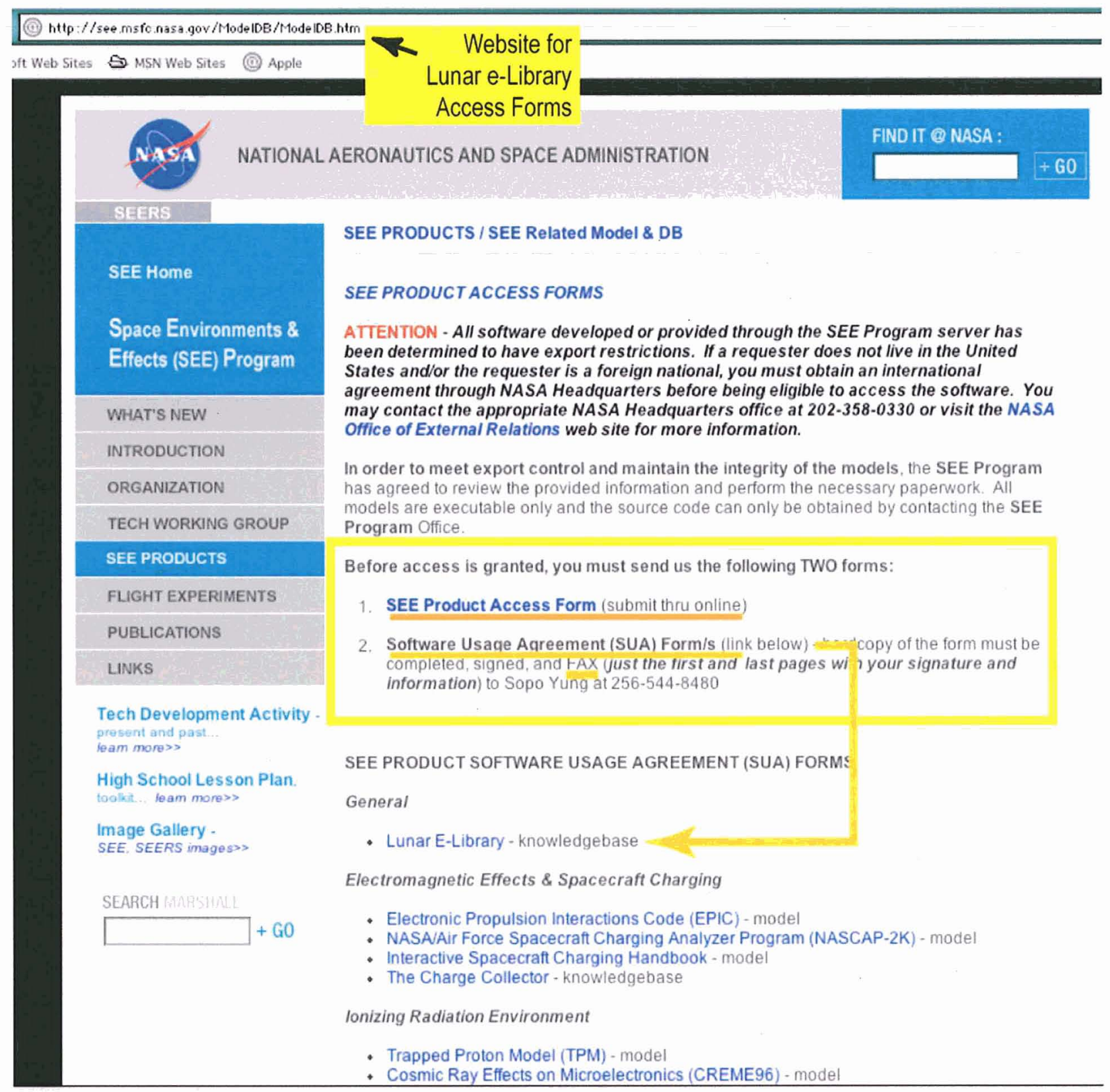

Figure 3. SEE web page with instructions for ordering the Lunar e-Library DVD.

\section{Using the Lunar e-Library Research Tool}

The Lunar e-Library can benefit research by providing access to numerous documents with information on the same topic. The library literature section contains a complete .PDF index. This index, which is organized alphabetically by title, can be searched to see the entire contents of the library. It is possible to find a particular document by searching by title, author, document number, or key words. This is an alternative way to find out which documents are included on the DVD. A sample page of the index is show in Fig. 4. 


\begin{tabular}{|c|c|c|c|c|c|}
\hline Document Title & Author (s) & $\begin{array}{l}\text { Document } \\
\text { \#/Source } \\
\text { Information }\end{array}$ & Keywords & $\begin{array}{l}\text { Publication } \\
\text { Date }\end{array}$ & Pages \\
\hline $\begin{array}{l}1965 \text { Publications by } \\
\text { Materials Division } \\
\text { (721) }\end{array}$ & Multiple authors & $\begin{array}{l}\text { NASA-TM- } \\
\text { X-53378 }\end{array}$ & $\begin{array}{l}\text { materials, composite, } \\
\text { elastomer, engineering, heat, } \\
\text { plastic, propellant, science } \\
\text { sensitivity, lubricants, } \\
\text { explosives, alloys }\end{array}$ & $1 / 13 / 1966$ & 25 \\
\hline $\begin{array}{l}\text { 2001 A Space } \\
\text { Odyssey Revisited. } \\
\text { The Feasibility of } 24 \\
\text { Hour Commuter } \\
\text { Flights to the Moon } \\
\text { Using NTR } \\
\text { Propulsion with } \\
\text { LUNOX } \\
\text { Afterburners; } \\
\text { Revisited (355) }\end{array}$ & $\begin{array}{l}\text { Borowski, } \\
\text { Stanley; } \\
\text { Dudzinski } \\
\text { Leonard A. }\end{array}$ & $\begin{array}{l}\text { NASA-TM- } \\
1996-208830\end{array}$ & $\begin{array}{l}\text { space, settlements, lunar, } \\
\text { moon, liquid oxygen, LOX, } \\
\text { nuclear, rockets, propulsion, } \\
\text { in situ resource utilization, } \\
\text { ISRU }\end{array}$ & $6 / 1 / 2003$ & 28 \\
\hline $\begin{array}{l}\text { A Balanced Model } \\
\text { for Exploration of the } \\
\text { Terrestrial Planets - } \\
\text { Lessons Learned } \\
\text { from the Lunar } \\
\text { Experience }(150)\end{array}$ & $\begin{array}{l}\text { Joliff B.L.; } \\
\text { Keller, L.P.; } \\
\text { MacPherson, } \\
\text { G.J.; Neal, C.R.; } \\
\text { Papanastassiouu, } \\
\text { D.A.; Ryder, G; } \\
\text { Shearer, C.K. }\end{array}$ & LPI-1062 & $\begin{array}{l}\text { lunar experience, Mars, in } \\
\text { situ resource utilization, } \\
\text { Apollo, Luna, Surveyor, } \\
\text { Clementine, Lunar } \\
\text { Prospector, Moon }\end{array}$ & $7 / 1 / 2002$ & 2 \\
\hline $\begin{array}{l}\text { A Center for } \\
\text { Extraterrestrial } \\
\text { Engineering and } \\
\text { Construction } \\
\text { (CETEC) }(816)\end{array}$ & $\begin{array}{l}\text { Leigh, Gerald G; } \\
\text { New Mexico } \\
\text { University; } \\
\text { Albuquerque, } \\
\text { NM, United } \\
\text { States }\end{array}$ & $\begin{array}{l}\text { N92-33309 } \\
24-12\end{array}$ & $\begin{array}{l}\text { lunar dust, construction, } \\
\text { engineering, environment, } \\
\text { simulation, extraterrestrial } \\
\text { environments, lunar } \\
\text { environment, lunar surface, } \\
\text { research facilities, lunar soil, } \\
\text { vacuum chambers, ground- } \\
\text { based testing, materials, } \\
\text { design }\end{array}$ & $1 / 1 / 1992$ & 33 \\
\hline $\begin{array}{l}\text { A Computer-Based } \\
\text { Orbital Debris } \\
\text { Environment Model } \\
\text { for Spacecraft Design } \\
\text { and Observation in } \\
\text { Low Earth Orbit } \\
\text { (224) }\end{array}$ & $\begin{array}{l}\text { Kessler, D.J.; } \\
\text { Zhang, J.; } \\
\text { Matney, M.J.; } \\
\text { Eichler, P.; } \\
\text { Reynolds, R.C.; } \\
\text { Anz-Meador, } \\
\text { P.D.; Stansbery, } \\
\text { E.G. }\end{array}$ & $\begin{array}{l}\text { NASA-TM- } \\
104825\end{array}$ & $\begin{array}{l}\text { space debris, orbital } \\
\text { mechanics, computer } \\
\text { modeling, space } \\
\text { environment, spacecraft } \\
\text { design, low-Earth orbit }\end{array}$ & $11 / 1 / 1996$ & 55 \\
\hline $\begin{array}{l}\text { A consideration of } \\
\text { lunar surface } \\
\text { ballistics (239) }\end{array}$ & Cramblit, D.C. & $\begin{array}{l}\text { NASA-TN- } \\
\text { D-1526 }\end{array}$ & $\begin{array}{l}\text { Lunar environment, base, } \\
\text { distribution, exhaust, film, } \\
\text { gas, high energy, inflation, } \\
\text { jet, landing, launch, manned, } \\
\text { moon, protection, sitting, } \\
\text { spacecraft, surface, thin, } \\
\text { velocity }\end{array}$ & $3 / 1 / 1963$ & 33 \\
\hline
\end{tabular}

Figure 4. Sample index page from Lunar e-Library literature section. 
The best way to search for information is by using the Lunar e-Library Search Engine. It is located by clicking on "Search Lunar e-Library" on the home page. Fig. 5 shows the sample results when searching the collection for the term "lunar dust." This search term resulted in 100 documents and appeared 174 times in those documents.

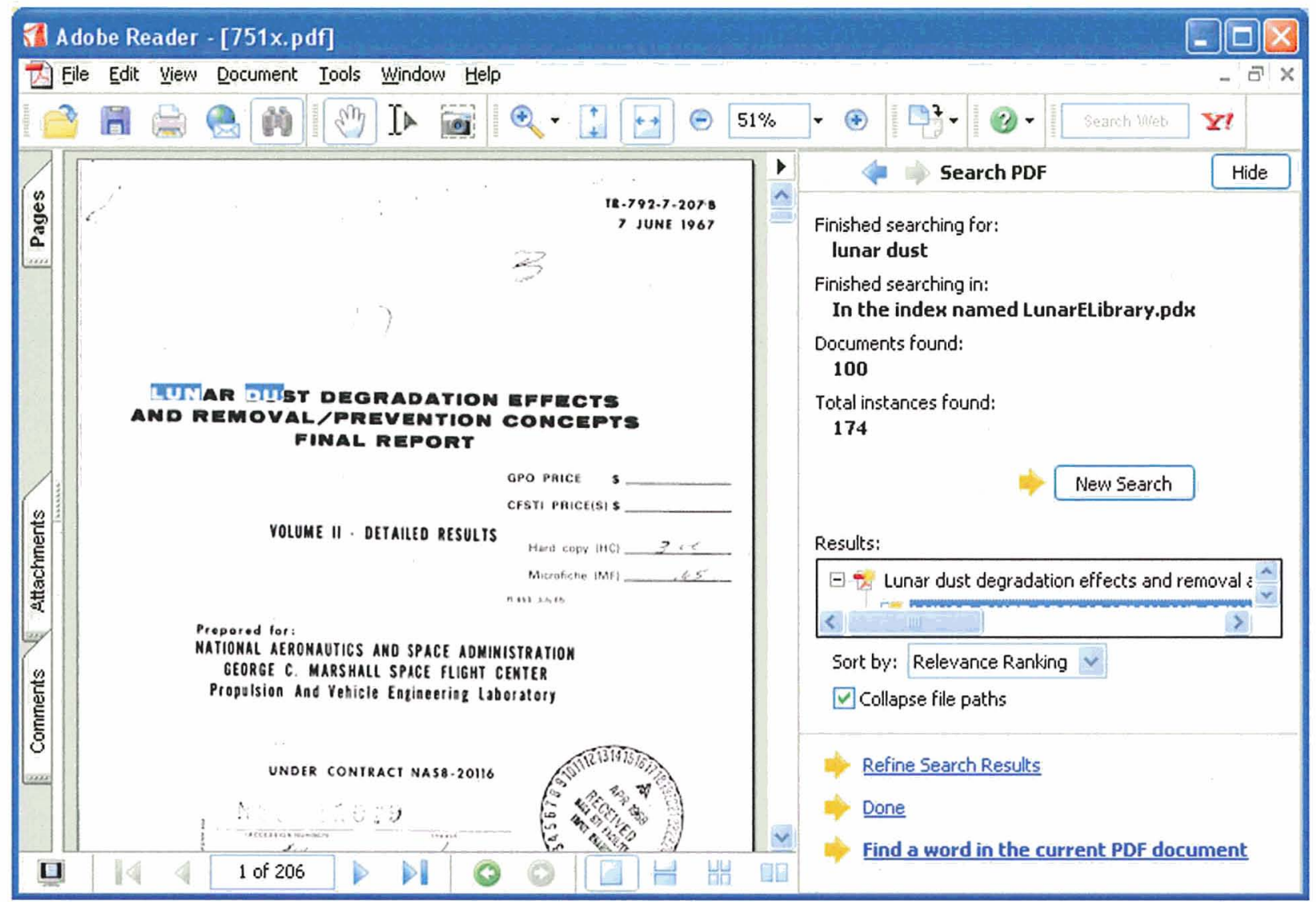

Figure 5. Results from lunar dust key word search.

To focus further focus the effort, a researcher can search within the results of a data set. For example, in the prior search for lunar dust, if the user clicks on "Refine Search Results, and uses "electrostatic charging" as the search term, the search engine looks in the current data set of 100 documents and finds 7 documents (out of the 100 identified by lunar dust in the prior search) with the search term appearing 7 times (Fig. 6). 


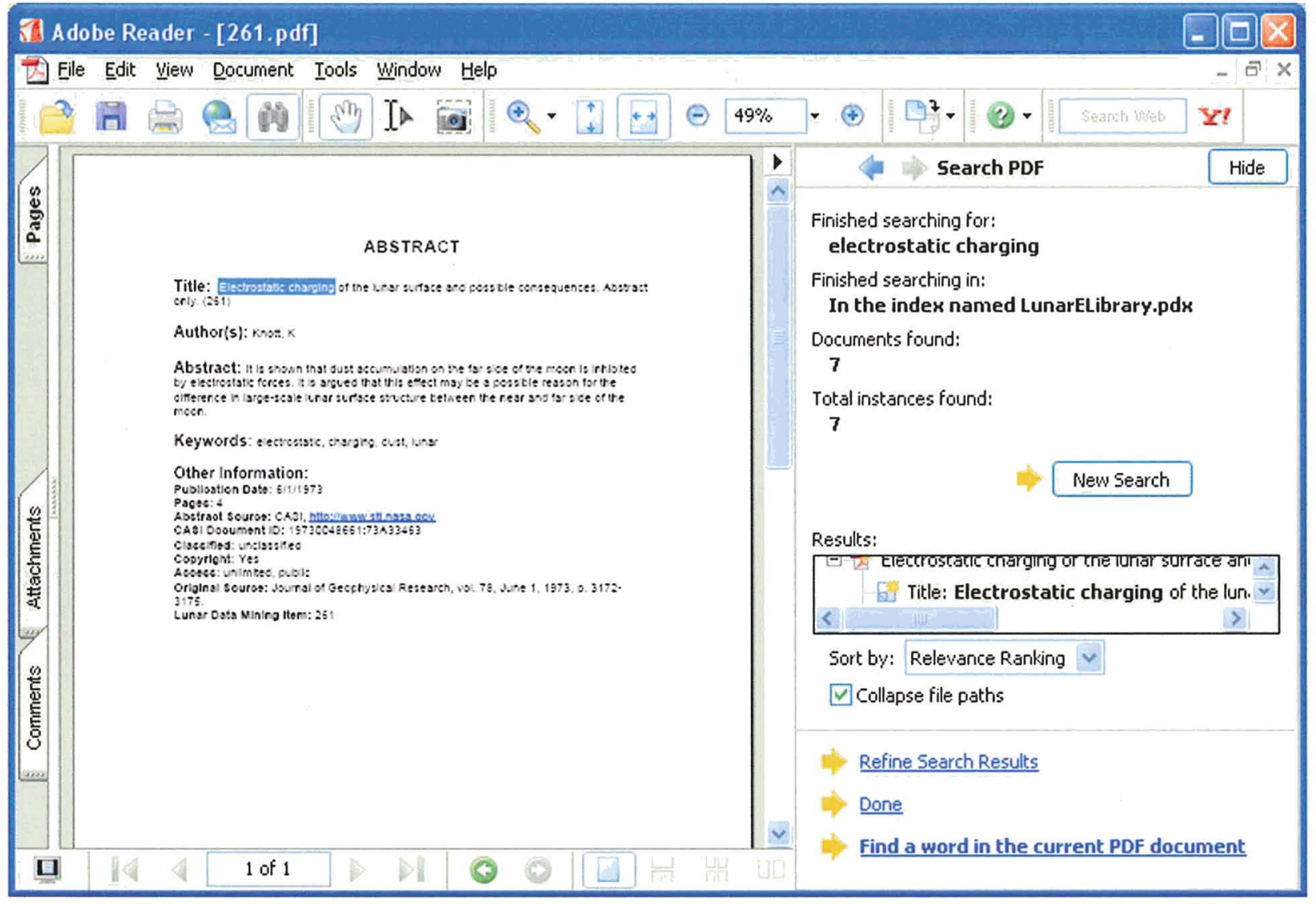

Figure 6. Refined search results using electrostatic charging key word search within the results set obtained by the "lunar dust" key word search.

Perhaps the researcher is interested in an astronaut's observations of the findings. Within the 100 documents found in the lunar dust search results, a search can be refined using the term Harrison Schmitt. A search using this term yields 6 documents with 11 appearances if of his name (Fig. 7). However, the search engine does search on the exact term or phrase that is entered, so more documents might be identified by searching on the astronaut's last name: Schmitt. Fig. 8 shows the refined search box, and Fig. 9 shows the result of the search for Schmitt, which yielded 17 documents with 167 references. 


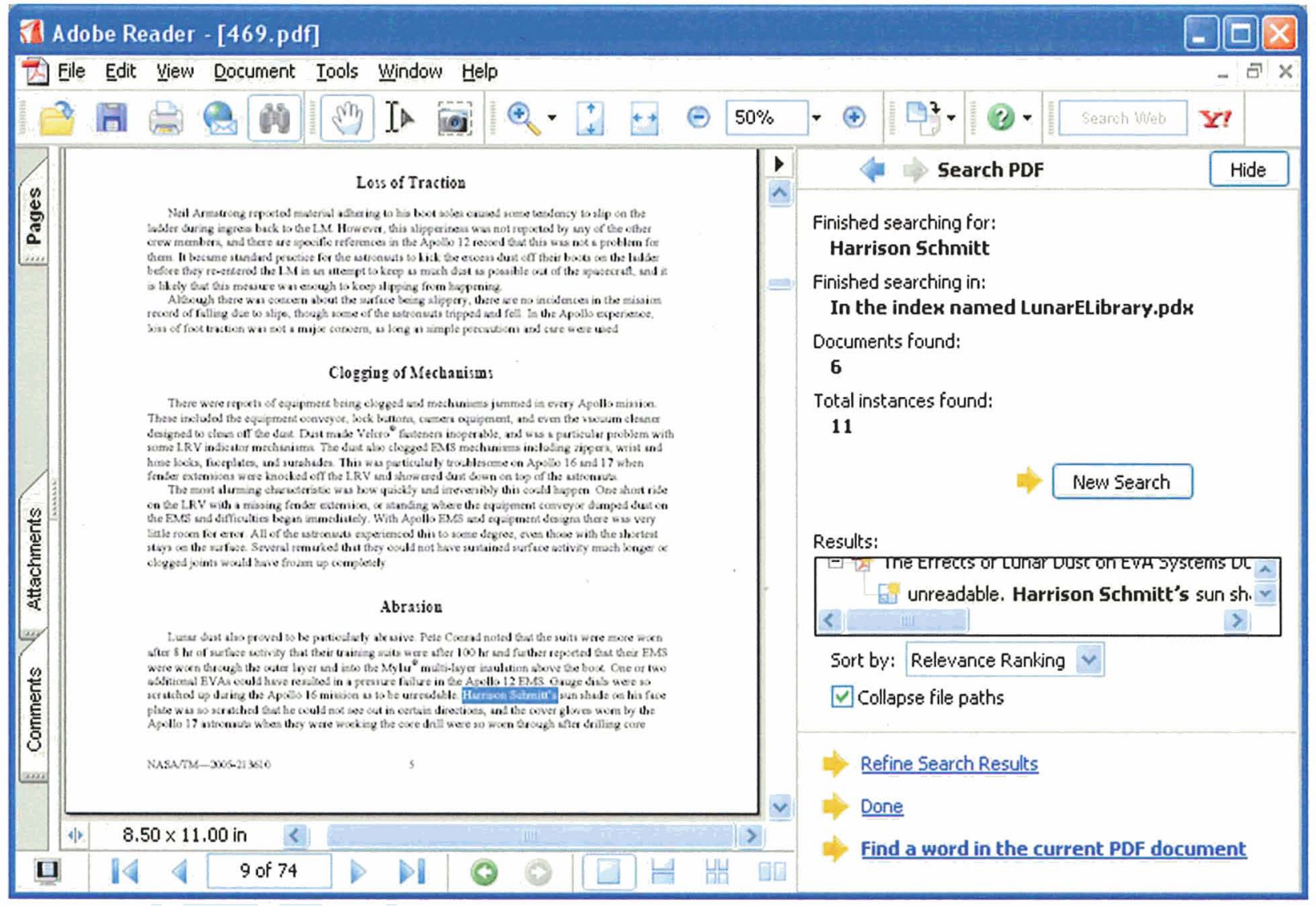

Figure 7. Results using "Harrison Schmitt" to search within documents found using "lunar dust" as the key word.

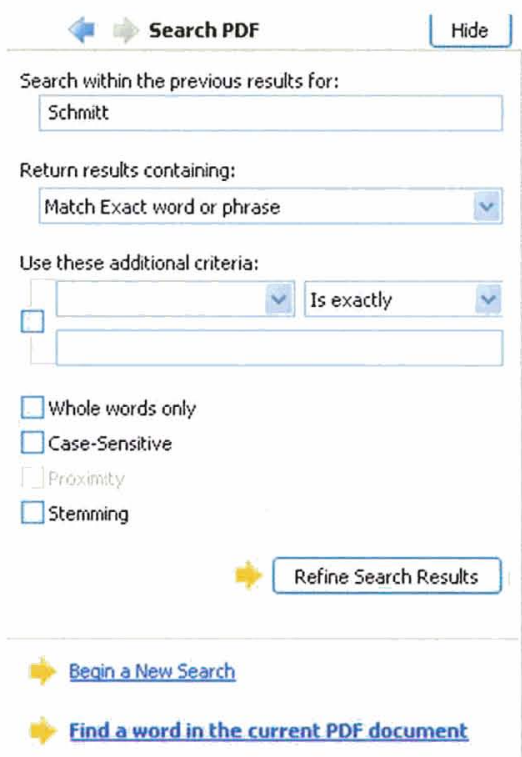

Figure 8. Refined search results using "Schmitt" as the search term.

American Institute of Aeronautics and Astronautics 


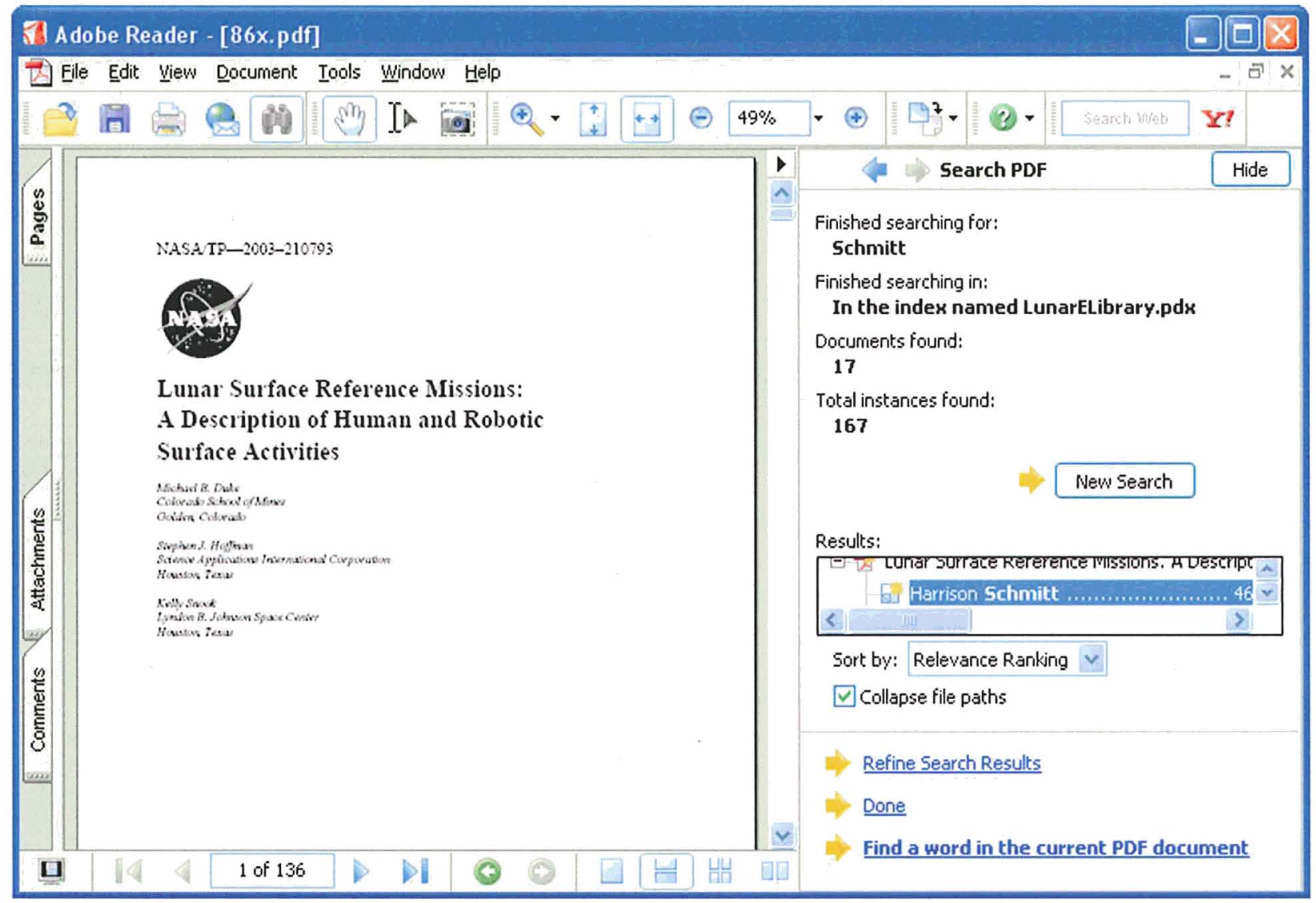

Figure 9. Search results using "Schmitt" as the key word.

Another example focused on the lunar environment would be the "lunar south pole." Other search terms in this area might be "South Pole-Aitken Basin" or "hydrogen" or even "lighting." Fig. 10 and Fig. 11 show some search results focused on examples that highlight lunar geography. 


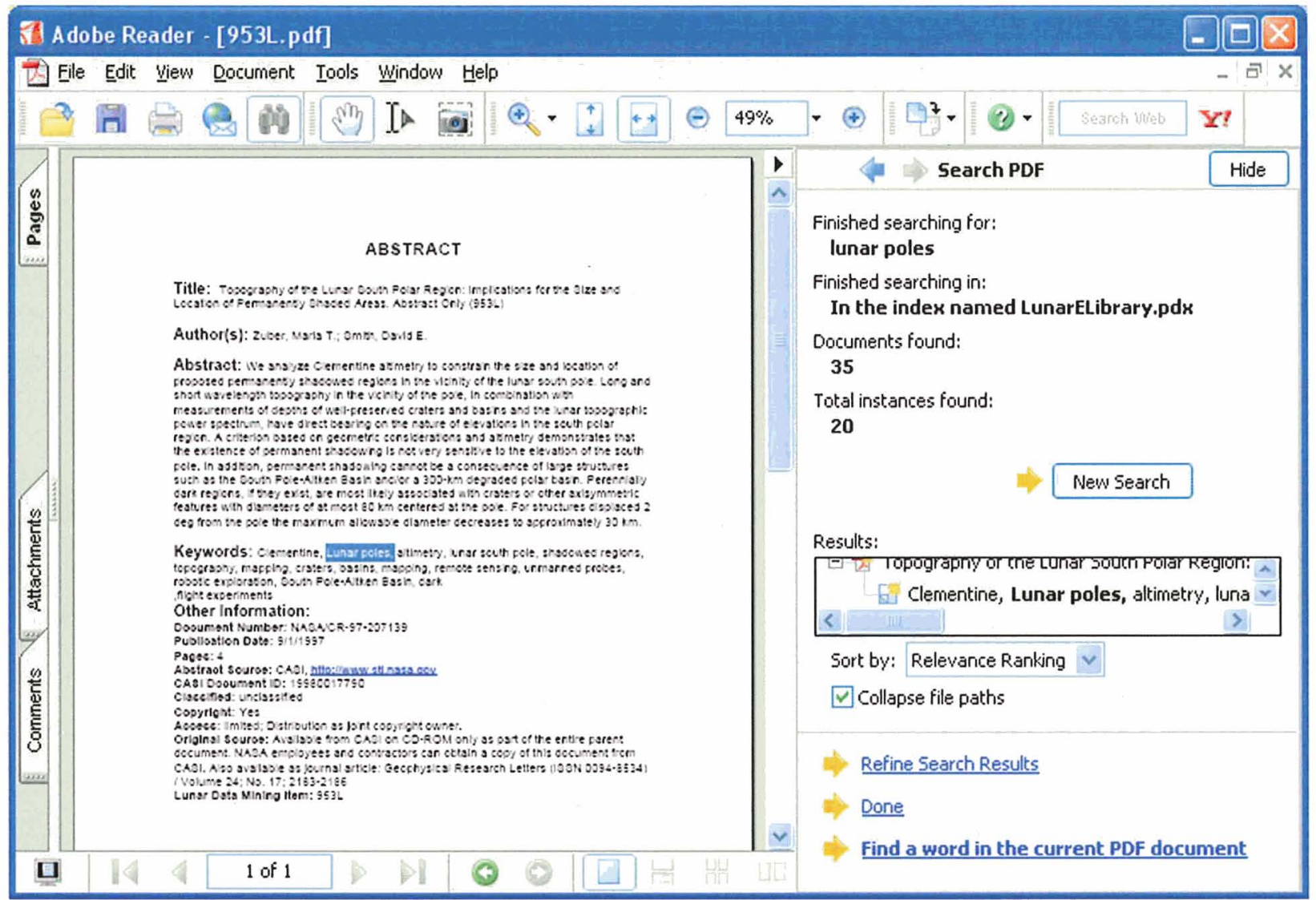

Figure 10. Search results using "Iunar poles" as the key word. 


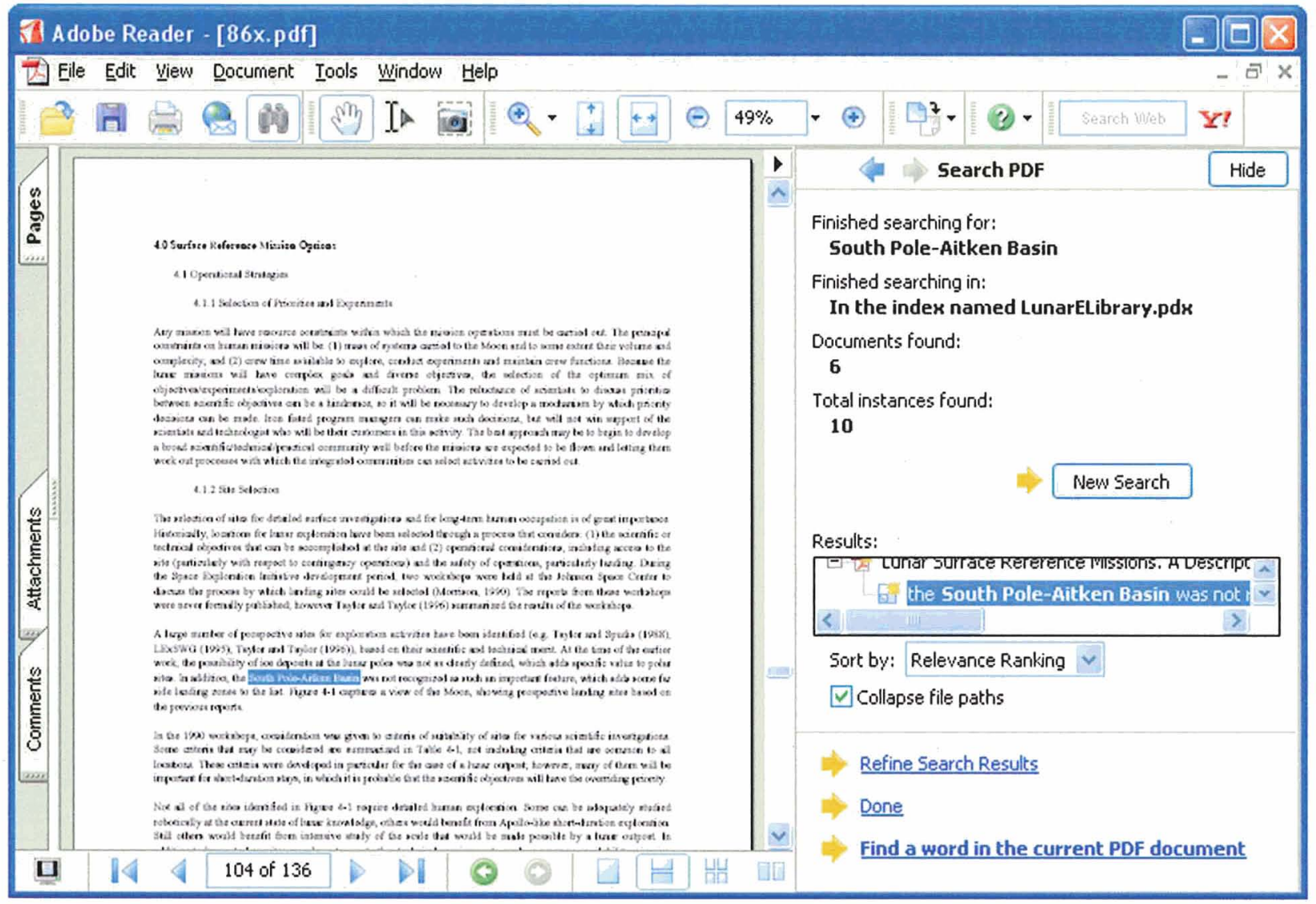

Figure 11. Search results using "South Pole-Aitken Basin" as the search term.

Another way to search is by document title. Perhaps the researcher wants to review the astronaut's observations included in all the Apollo Preliminary Science Reports. First, a search can be conducted on "Apollo Preliminary Science Report" using the title feature in the advanced search function. Then a search can be conducted on "crew observations." This will take the researcher directly to the sections in these reports where the crew members recorded their observations, or if a researcher is only interested in locating the observations of particular crew members, searches can be conducted using astronaut names.

Researchers interested in everything written by a particular author can search using the author option or even use the author's name as a key word. It is often advisable to use the last name only or all the variations of an author's name because publications may contain more than one form of the name. For example for scientist Mike Duke, publications are also listed under Michael Duke and M.B. Duke. If you use the last name only, you will get a broader data set that includes other people with the same last name, but the data set will include more hits for the desired author.

As the examples in this section demonstrate, the DVD search engine is designed to give the user many ways to search for information and compile data sets relevant to a particular topic.

\section{V. $\square$ Conclusion}

The Vision for Space Exploration comprises a broad range of missions - from robotic to human - and requires a vast number of technologies in every engineering discipline. Success will depend upon combining experience (historical knowledge) and innovative thinking. Since the vision will be sustained over decades, information must 
not only be accessible to current aerospace professionals but also must be available to guide young engineers who join the journey. The Lunar e-Library DVD knowledgebase is a research tool that will bolster NASA's return to the Moon.

\section{VI. $\square$ Acknowledgments}

The authors would like to acknowledge Dr. Robby Newton, Dr. Dale Ferguson, Dr. David Edwards and Tim Vaughn for providing leadership in developing the Lunar e-Library. Sopo Yung, a talented computer engineer with Morgan Research Company, selected the Acrobat search engine feature, programmed the product, and is producing and distributing the DVD. The team relied heavily on the excellent document tracking and review system specially designed for this project by Casey Watkins, a young chemical engineer with Qualis Corporation. Dr. Rose Norman, a technical writing professor at the University of Alabama in Huntsville (UAH), gave us the opportunity to work with her brilliant students who helped us evaluate the UAH archive collection and transcribe interview notes. NASA historians and experts, such as Michael Wright, the MSFC Historian, and Anne Coleman, who manages the Saturn $\mathrm{V}$ and Lunar Roving Vehicle archives at UAH, gave invaluable direction that saved time. The MSFC Multimedia Group provided excellent support in documenting and preserving the interviews. Last, but certainly not least, we want to thank the interview subjects who were willing to share their time and knowledge to provide invaluable wisdom for current and future engineers and scientists. They truly embody the best of NASA and offer us all the inspiration needed to forge onward to the stars. 